\title{
Linfonodo-sentinela no câncer de mama acessória: relato de caso
}

\author{
Sentinel lymph node in accessory breast cancer: a case report
}

Daniel Guimarães Tiezzi ${ }^{1}$, Fernando Antonio Mourão Valejo², Gisele Alborgheti Nai ${ }^{3}$, Marcelo Guimarães Tiezzi ${ }^{4}$

\section{RESUMO}

No último século, grandes avanços foram surgindo na forma de tratar o câncer de mama. A remoção radical da glândula e das estruturas adjacentes tem sido substituída por cirurgias conservadoras e a abordagem cirúrgica dos linfonodos axilares vem se tornando fundamental. Relatamos o caso de paciente com câncer de mama ectópica na axila esquerda e a identificação do linfonodo-sentinela pela técnica do azul patente. Discutimos os estudos relacionados à drenagem linfática do tecido mamário ectópico e a identificação do linfonodo-sentinela nesta rara situação.

PALAVRAS-CHAVE: Biópsia de linfonodo-sentinela; Neoplasias mamárias; Mama/anormalidades; Metástase linfática; Vasos linfáticos; Relatos de casos [tipo publicação]

\section{ABSTRACT}

During the last century, remarkable progress has been made in the treatment of breast cancer. Radical surgical removal of the breast and surrounding structures has been replaced by conservative surgery and the surgical management of axillary lymphnodes has been fundamental. We report a case of a patient with an ectopic breast cancer in the left axilla and sentinel lymphnode identification by the patent blue dye technique. The studies about lymphatic drainage of the ectopic mammary tissue and sentinel lymph node identification in this rare situation were also reviewed.

KEYWORDS: Sentinel lymph node biopsy; Breast neoplasms; Breast/abnormalities; Lymphatic metastasis; Lymphatic vessels; Case reports [Publication type]

\section{Introdução}

A incidência de polimastia na população geral varia de 2 a $6 \%{ }^{1}$, sendo as mamas acessórias, na quase totalidade das vezes, consideradas como um problema meramente estético. Entretanto, essas estruturas, como qualquer tecido mamário, podem ser alvo de alterações patológicas variadas, benignas ou malignas, uma vez que respondem às variações hormonais fisiológicas e estão sujeitas aos mesmos agentes carcinogênicos. Representando 0,3\% dos carcinomas mamários ${ }^{2}$, o câncer de mama ectópica é um problema real e deve ser divulgado, já que sua baixa freqüência na população pode tornar o diagnóstico dificil de ser feito.

Durante os últimos anos, grandes avanços foram surgindo na forma de tratar o câncer de mama. As grandes cirurgias radicais foram substituídas por tratamentos conservadores e, na atualidade, a abordagem cirúrgica para avaliação do envolvimento de linfonodos axilares tem sido objeto de estudo. Acreditase que o envolvimento dos linfonodos ocorre continuamente, um a um, da periferia para a região medial da axila ${ }^{3}$. Sendo assim, estão surgindo métodos de predição de acometimento axilar através de procedimentos pouco invasivos, como a avaliação do linfonodo-sentinela, que permite evitar a linfadenectomia e seus efeitos colaterais em pacientes com axila negativa ${ }^{4}$.

\footnotetext{
Trabalho realizado no Serviço de Mastologia da Universidade do Oeste Paulista - UNOEST - Presidente Prudente (SP), Brasil.

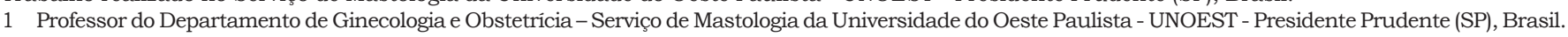

2 Residente do Departamento de Ginecologia e Obstetricia da Universidade do Oeste Paulista - UNOEST - Presidente Prudente (SP), Brasil.

3 Professora do Departamento de Patologia da Universidade do Oeste Paulista - UNOEST - Presidente Prudente (SP), Brasil.

4 Médico Patologista do Laboratório de Anatomia Patológica e Citopatologia de Presidente Prudente - Presidente Prudente (SP), Brasil.

Correspondência: Fernando Antonio Mourão Valejo

Rua Tambaú, 36, apto. 62 - Vila Cristina - 19013-340 - Presidente Prudente - SP - e-mail: fvalejo.ig@ig.com.br

Recebido em: 2/8/2005 Aceito com modificações em: 16/1/2006
}

Rev Bras Ginecol Obstet. 2006;28(1):50-3 
O conceito de linfonodo-sentinela foi relatado inicialmente por Virchow em meados do século dezenove sendo Braithwaite o primeiro a usar o termo "glândula sentinela" em $1923^{5}$. Objeto de vários estudos atualmente, a biópsia do linfonodosentinela, independentemente da técnica utilizada, tem alta acurácia (92 a 100\%), e relativamente baixa taxa de falso-negativo (0 a 19\%), além de baixas taxas de recorrência local em mulheres com axila preservada após biópsia negativa do linfonodo-sentinela ${ }^{6,7}$. Apesar disso, em uma pequena porcentagem dos pacientes é observada a presença de metástase em outros linfonodos que não o linfonodo-sentinela. Outro problema descrito na técnica de avaliação do linfonodo-sentinela é a presença de metástase nos linfonodos axilares dos niveis II e III sem envolvimento dos linfonodos do nivel I, a chamada skip metastasis, relatada em 1,5 a $29,2 \%{ }^{8,9}$ dos casos.

Como o câncer no tecido mamário ectópico é uma patologia rara, o estudo do linfonodo-sentinela nesses casos ainda é escasso e a anatomia da drenagem linfática desses tumores ainda não está esclarecida. Assim, faz-se necessário relatar os casos encontrados e revisar, sempre que possivel, a drenagem linfática relacionada a este tipo de tumor.

\section{Relato do Caso}

M.J.R., 69 anos, sexo feminino, procurou o ambulatório de Mastologia do Hospital Universitário da Universidade do Oeste Paulista no dia 22 de junho de 2004, com queixa de massa axilar bilateral, notada na infância, que aumentou de tamanho durante os períodos de gravidez e amamentação, indolor, que era motivo de constrangimento pessoal. Negava dor, alteração cutânea ou tumoração local. Antecedentes pessoais: hipertensa há 19 anos. Nega diabetes, doenças tromboembólicas, cirurgias prévias, tabagismo e etilismo. Faz uso de metildopa e hidroclorotiazida há 18 anos. Antecedentes obstétricos: G IX, P VII, A II, partos normais, domiciliares, sem doença associada. Abortos espontâneos. Primeiro parto aos 17 anos. Amamentou todos os filhos durante 10 meses em média. Antecedentes ginecológicos: menarca aos 13 anos, menopausa aos 59 anos, nunca fez uso de hormonioterapia (contraceptivos ou TRH). Sempre teve ciclos regulares de 28 dias em média. Antecedentes familiares: pais falecidos por problemas cardiovasculares. Desconhece história de câncer na família. Não sabe relatar doença em irmãos. Ao exame físico, observamos a presença de mamas supranumerárias bilateralmente, fixas na linha axilar anterior (Figura 1). A palpação da mama supranumerária esquerda revelou presença de massa de consistência nodular, formato oval, dolorosa e de contornos mal definidos. As duas mamas tópicas e a mama supranumerária direita não apresentavam alteração. Ao exame da axila não havia linfonodos palpáveis. A paciente foi submetida a mamografia, que revelou corpos mamários tópicos de morfologia e contornos usuais, apresentando parênquima com padrão de lipossubstituição, sem alteração sugestiva de doença. Notava-se presença de mamas supranumerárias axilares bilaterais, sendo que a esquerda apresentava lesão nodular de alta densidade com limites imprecisos e bordos espiculados. A mama ectópica direita apresentava padrão de lipossubstituição, onde não se evidenciavam alterações. Classificação BI-RADS V (Figura 2). A punção aspirativa com agulha fina da lesão revelou quadro citológico compatível com carcinoma.

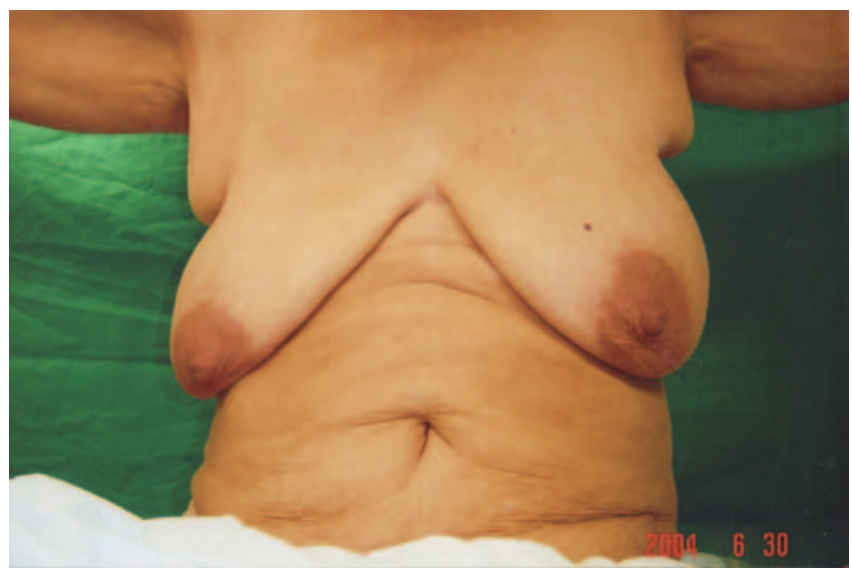

Figura 1 - Pré-operatório. Presença de mama acessória axilar bilateral.

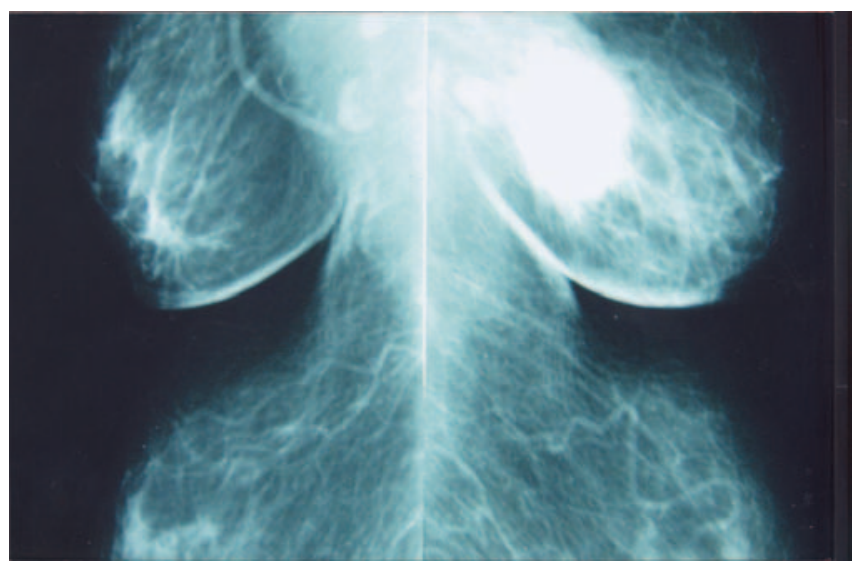

Figura 2 - Mamografia pré-operatória. Presença de lesão nodular de alta densidade radiológica, limites imprecisos e bordos espiculados em mama axilar esquerda.

Foi submetida a procedimento cirúrgico para ressecção das mamas acessórias. À esquerda utilizamos a técnica do azul patente V para identifi- 
cação do linfonodo-sentinela. Procedeu-se à infiltração de $1 \mathrm{~mL}$ do corante azul patente $\mathrm{V}$ (Gerbet) na subderme sobrejacente ao tumor da mama axilar esquerda. Realizada incisão axilar de $4 \mathrm{~cm}$ de extensão com abordagem da axila e identificação e remoção do ducto linfático aferente e do linfonodo-sentinela (Figura 3). Realizamos a ressecção completa das mamas acessórias esquerda e direita, bem como a linfadenectomia axilar esquerda em niveis I, II e III. Os linfonodos foram colocados em frascos separados, identificados conforme o nivel dissecado e encaminhados para estudo anatomopatológico. O linfonodo-sentinela foi encaminhado separadamente.

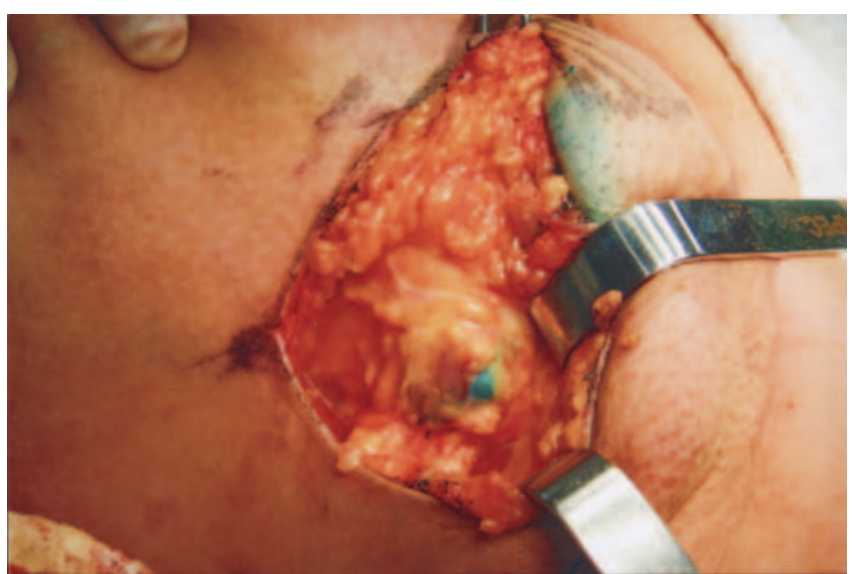

Figura 3 - Identificação do ducto linfático aferente e do linfonodo-sentinela.

O exame anatomopatológico revelou presença de carcinoma ductal invasivo de grau II de Bloom e Richardson, medindo $4 \times 3,5 \times 2 \mathrm{~cm}$, de contornos regulares, com moderado infiltrado linfoplasmocitário no estroma tumoral. Ausência de invasão angiolinfática e de extensão para a pele da mama. A margem cirúrgica profunda era escassa (menor que $1 \mathrm{~mm}$ ). Ausência de metástase para o linfonodo-sentinela e para os 2 linfonodos dissecados do nível I. Presença de metástase em 1 dos 7 linfonodos dissecados do nível II e ausência de metástase para os 4 linfonodos do nivel III. $\mathrm{Na}$ mama acessória direita foi encontrado apenas cistificação de ductos. Todos os linfonodos foram submetidos à técnica de imuno-histoquímica padrão utilizando anticorpo primário anticitoqueratina para pesquisa de micrometástases e pesquisa de receptores hormonais. Não foram identificadas micrometástases no linfonodo-sentinela e em nenhum outro linfonodo do nível I, sendo confirmada a presença de metástase em um linfonodo do nivel II. Os receptores para estrogênio e progestagênio foram positivos. A paciente evoluiu sem intercorrências no pós-operatório e foi submetida a radioterapia adjuvante. Os campos utilizados foram o parênquima mamário residual ho- molateral (5.000 cGy) com reforço da dose boost na área onde foi excisada a mama supranumerária. A paciente encontra-se em uso de hormonioterapia adjuvante com tamoxifeno $20 \mathrm{mg}$ via oral ao dia. Após 12 meses de seguimento, a paciente não apresenta sinais de recidiva tumoral.

\section{Discussão}

A anatomia do sistema linfático das mamas tem sido estudada por muitos séculos. Em 1830, Sappey concluiu que a maioria do tecido mamário drenaria de forma centripeta para um plexo subareolar e deste, para a axila. Posteriormente, anatomistas mostraram que o conceito de Sappey estava incompleto e que vias linfáticas adicionais existiam. Vasos linfáticos profundos partem da face posterior da mama, passam através dos músculos peitorais e intercostais e alcançam uma cadeia de linfonodos existente ao longo dos vasos mamários, chamada cadeia mamária interna ${ }^{10,11}$. Há ainda a possibilidade da drenagem direta do parênquima mamário para linfonodos supraclaviculares e drenagem para a cadeia mamária interna contralateral por via retroesternal, caso haja obstrução da drenagem axilar homolateral causada por tumor, cicatriz cirúrgica ou radiação. Mostrou-se ainda que os linfonodos intercostais posteriores podem receber drenagem linfática da mama em número pequeno de casos, bem como os linfonodos intercostais anteriores. Apesar desta rica anatomia, é consenso que a axila é o principal local de drenagem linfática da mama e que os linfonodos axilares recebem mais de $75 \%$ de toda drenagem linfática da mama homolateral ${ }^{10}$.

A rede linfática mamária é dividida nos plexos superficial ou subareolar (de Sappey) e profundo ou fascial. O plexo superficial coleta a linfa proveniente das porções centrais da mama, da pele, da aréola e da papila mamária, drenando, em sua maior parte, lateralmente em direção à axila, o que corresponde a $97 \%$ da drenagem linfática da mama. O plexo profundo possui uma parte que se estende entre os músculos peitorais maior e menor, drenando para os linfonodos subclávios (via de Groszman), e a maior parte drena para os linfonodos mamários internos e daí, para os linfonodos mediastinais. Existem outras vias de drenagem linfática que provêm principalmente de regiões inferomediais da mama: a rota paramamária de Gerota, que através de linfáticos abdominais drena para o figado e linfonodos diafragmáticos, a via transmamária, que drena para mamas e axilas opostas, e ainda alguns vasos profundos que podem drenar aos linfonodos mediastinais anteriores, que estão situados anteriormente à aorta, passando pelo esterno ${ }^{12}$. 
A introdução da técnica do linfonodo-sentinela na mastologia atual tem promovido crescente interesse no estudo da anatomia e fisiologia do sistema linfático da mama. $O$ conceito de que ambas as mamas e a pele que as recobre possuem um caminho de drenagem linfática comum para o mesmo linfonodo ${ }^{13}$ tem sido estudado por quase um século. Porém alguns estudos têm mostrado o aparecimento de metástase em níveis II e III sem evidência de acometimento ganglionar no nivel I, as chamadas skip metastase ${ }^{14}$.

Por sessenta anos, enquanto o tratamento do câncer de mama era invariavelmente feito com mastectomia radical, com ressecção em bloco de todo o conteúdo linfático axilar, a existência de skip metastases não era considerada ${ }^{3}$. Entretanto, sua incidência passou a ser estudada a partir do momento em que se passou a realizar tratamentos mais conservadores para esse tipo de doença, em especial a avaliação do linfonodo-sentinela.

Atualmente existem na literatura dois casos relatando o uso da técnica do linfonodo-sentinela no tratamento de câncer de mama acessória. Thorne et al. ${ }^{15}$ relataram o caso de paciente de 59 anos que apresentava mama acessória no lado esquerdo da parede abdominal, onde foi encontrado um tumor cujo exame anatomopatológico revelou se tratar de adenocarcinoma. A linfocintilografia mostrou quatro áreas de drenagem: mama tópica esquerda, axila esquerda, cadeia mamária interna e região inguinal esquerda. Foram identificados e retirados linfonodos-sentinela na mama tópica esquerda e na axila. Um dos três linfonodos-sentinela identificados na mama esquerda apresentavam metástase. O linfonodo-sentinela axilar não estava comprometido.

Gentilini et al. ${ }^{16}$ relataram o caso de paciente que apresentava câncer em tecido mamário ectópico presente na região paraesternal. Foi realizada linfocintilografia identificando drenagem para linfonodos da axila homo e contralateral ao tumor primário. A localização radioguiada do linfonodo-sentinela foi realizada bilateralmente e foram encontradas metástases bilaterais.

De fato, conforme nossos achados, além dos relatos de Gentilini et al. ${ }^{16}$ e Thorne et al.15, parece que a drenagem do tecido mamário ectópico não segue o padrão descrito para a drenagem da mama tópica. É provável que haja drenagens múltiplas, o que dificulta a utilização de corantes para identificação do linfonodo-sentinela. Como não existe na literatura estudo que defina a anatomia linfática de mamas acessórias, a pesquisa do linfonodo-sentinela pela técnica do corante azul deve ser evitada, havendo, assim, a necessidade de estudos controlados para a segurança da utilização desta técnica.

\section{Referências}

1. Giron GL, Friedman I, Feldman S. Lobular carcinoma in ectopic axillary breast tissue. Am Surg. 2004;70(4):312-5.

2. Gilmore HT, Milroy M, Mello BJ. Supernumerary nipples and accessory breast tissue. S D J Med. 1996;49(5):149-51.

3. Rosen PP, Lesser ML, Kinne DW, Beattie EJ. Discontinuous or "skip" metastases in breast carcinoma. Analysis of 1228 axillary dissections. Ann Surg. 1983;197(3):276-83.

4. Veronesi U, Paganelli G, Viale G, Luini A, Zurrida $\mathrm{S}$, Galimberti V, et al. A randomized comparison of sentinel-node biopsy with routine axillary dissection in breast cancer. N Engl J Med. 2003;349(6):546-53.

5. Thompson JF, Uren RF, Scolyer RA, Stretch JR. Selective sentinel lymphadenectomy: progress to date and prospects for the future. Cancer Treat Res. 2005;127(1):269-87.

6. Kelley MC, Hansen N, McMasters KM. Lymphatic mapping and sentinel lymphadenectomy for breast cancer. Am J Surg. 2004;188(1):49-61.

7. Gurleyik G, Aker F, Sekmen U, Saglam A. Accuracy of sentinel lymph node biopsy for the assessment of axillary status in patients with early (t1) breast carcinoma. J Coll Physicians Surg Pak. 2005;15(11):697-700.

8. Veronesi U, Rilke F, Luini A, Sacchini V, Galimberti $\mathrm{V}$, Campa T, et al. Distribution of axillary node metastases by level of invasion: an analysis of 539 cases. Cancer. 1987;59(4):682-7.

9. Danforth DN Jr, Findlay PA, McDonald HD, Lippman $\mathrm{ME}$, Reichert CM, d'Angelo T, et al. Complete axillary lymph node dissection for stage I-II carcinoma of the breast. J Clin Oncol. 1986;4(5):655-62.

10. Tanis PJ, Nieweg OE, Valdes Olmos RA, Kroon BB. Anatomy and physiology of lymphatic drainage of the breast from the perspective of sentinel node biopsy. J Am Coll Surg. 2001;192(3):399-409.

11. Servelle M, Bourdin JS, Zafari I, Soulie J, Andrieux $\mathrm{J}$, Merceron B, et al. The lymphatics of the breast and pectoral muscles. Sem Hop. 1972;48(2):121-7.

12. Baracat EC, Nazário ACP, Simões MJ. Morfologia e fisiologia da mama. In: Piato S, editor. Mastologia. São Paulo: Roca; 1995. p. 5.

13. Borgstein PJ, Meijer S, Pijpers R. Intradermal blue dye to identify the sentinel lymph-node in breast cancer. Lancet. 1997;349(9066):1668-9.

14. Lloyd LR, Waits RK Jr, Schroder D, Hawasli A, Rizzo P, Rizzo J. Axillary dissection for breast carcinoma: the myth of skip metastasis. Am Surg. 1989;55(6):381-4.

15. Thorne AL, Jackson A, Yiangou C. The use of sentinel node biopsy in the treatment of cancer of an accessory breast. Breast. 2003;12(2):153-5.

16. Gentilini O, Paganelli G, Trifiro G, Veronesi P. Sentinel node biopsy in ectopic breast cancer. Nucl Med Commun. 2003;24(11):1127-8. 